\title{
Novel non-cytotoxic alginate-lignin hybrid aerogels as scaffolds for tissue engineering
}

\author{
3 Q1 Sakeena Quraishi $^{\mathrm{a}}$, Marta Martins ${ }^{\mathrm{b}, \mathrm{c}}$, Alexandre A. Barros ${ }^{\mathrm{b}, \mathrm{c}}$, Pavel Gurikov ${ }^{\mathrm{a}, *}$, \\ S.P. Raman ${ }^{a}$, Irina Smirnova ${ }^{a}$, Ana Rita C. Duarte ${ }^{\mathrm{b}, \mathrm{c}}$, Rui L. Reis ${ }^{\mathrm{b}, \mathrm{c}}$ \\ ${ }^{a}$ Hamburg University of Technology, Institute of Thermal Separation Processes, Eißendorfer Straße 38, 21073 Hamburg, Germany \\ b 3B's Research Group - Biomaterials, Biodegradables and Biomimetics, University of Minho, Headquarters of the European Institute of Excellence on Tissue \\ Engineering and Regenerative Medicine, AvePark, 4806-909 Taipas, Guimarães, Portugal \\ c ICVS/3B's - PT Government Associate Laboratory, Braga, Guimarães, Portugal
}

\section{Introduction}

Since discovered in 1930s, aerogels, ultra-light open-porous materials, have been gaining a great deal of attention in the foreground of material science and emerging technology. Attempts have recently been made to address a variety of regenerative medicine problems using aerogels as scaffolds $[1,2]$. Several polymers have been used as precursors to produce aerogel-based tissue engineering scaffolds: PLA [3], chitosan [4-6], and polyurea

Abbreviations:

BET, Brunauer-Emmett-Teller model; BJH, Barrett-Joyner-Halenda model; $q$, crosslinking degree; DMEM, Dulbecco's modified Eagle's medium; G, guluronic acid; $\mathrm{IC}_{50}, 50 \%$ inhibitory concentration; M, mannuronic; Micro-CT, micro-computed tomography; MTS, 3-(4,5-dimethylthiazol-2-yl)-5-(3-carboxymethoxyphenyl)-2-(4-sulphophenyl)2H-tetrazolium; Na-Alg, sodium alginate; PBS, phosphate buffered saline; PEG, polyethylene glycol; PLA, poly-(L-lactic acid); PMS, phenazine methosulphate; PVA, polyvinyl alcohol; PVP, polyvinylpyrrolidone; TCP, tissue culture polystyrene; TRIS, tris(hydroxymethyl)aminomethane.

Q2 * Corresponding author. Tel.: +49 40428784275; fax: +49 40428783642.

E-mail address: pavel.gurikov@tuhh.de (P. Gurikov). crosslinked silica [7-9]. The latter material has been extensively assessed in vivo.

Alginate is a well-known biomaterial and is widely used for drug delivery [10] and in tissue engineering [11,12] due to its biocompatibility, low toxicity, relatively low cost and simple gelation mechanism [13]. It is a polysaccharide comprising of mannuronic $(\mathrm{M})$ acid and guluronic $(\mathrm{G})$ acid residues obtained either from brown algae or from bacterial sources [14]. Owing to its gelling, thickening, stabilizing and viscosifying properties, alginate is a prominent component for food [15], textile and paper industries $[16,17]$ as well as in pharmaceutical and medical fields $[10,18,19]$. However, due to the hydrophilic nature of the alginate chains, the protein adsorption is discouraged leading to the hampered the cell adhesion and thus limiting potential tissue engineering applications $[20,21]$. Attempts have been presented in the literature to overcome this limitation including chemical grafting with oligopeptides [20,22]; blending with other biopolymers [23,24] and addition of hydroxyapatite [25]. In this work it was attempted to exploit a major constituent of lignocellulosic biomass, namely lignin, to produce hybrid alginate-lignin aerogels with the prospect of biomedical relevance. As pointed out by Smetana [26], the ratio 
56 between hydrophilicity and hydrophobicity of the surface is an important factor of cell adhesion. Lignin is expected to reduce hydrophilicity of alginate and hence provide more suitable environment for cells to adhere, grow and differentiate. Bearing in mind ultimate stability of lignin, it was also expected that the presence of lignin may abate the scaffold degradation rate and help to match it with the rate of new bone tissue regeneration.

Due to its abundance and low price, it is of definite interest to usher lignin into high-value products, i.e. biomaterials, adsorbents, thermal insulators. Several attempts have been reported in the literature on lignin as a part of biomaterials exemplified by composites with hydroxyapatite $[27,28]$; as a carrier in laxative formulations [29]; allergenicity reducer for latex rubber [30]. Potential applications in food industry are also reported [31]. For comprehensive overview on other application of lignin and ligninbased products readers are referred to recently published reviews [32-34].

One objection against lignin as a material for biomedical and pharmaceutical applications is its phenolic nature. Organosolv lignin has been reported to be slightly cytotoxic for peripheral blood mononuclear cells [28]. One lignin derivative, sulphonated lignin, when blended with fish gelatin, showed cytotoxicity only at very high concentrations $\left(\mathrm{IC}_{50}\right.$ in the range $1500-1750 \mu \mathrm{g} / \mathrm{ml}$ ) [31]. $\mathrm{IC}_{50}$ values in the range of $400-1200 \mu \mathrm{g} / \mathrm{ml}$ were found for lignins from different sources by Ugartondo et al. [35]. Microalgae (Chlamydomonas reinhardtii) and Backer's yeast (Saccharomyces cerevisiae) show indistinguishable loss of viability after incubation with lignin nanoparticles compare with a control sample [36]. From this data it can be surmised that generally lignin is not cytotoxic up to moderate concentration. One aim of this work is to prove whether Ca-crosslinked alginate-lignin aerogels are non-cytotoxic and to evaluate them as potential biomaterials.

Apart from lower hydrophilicity and higher stability another potential advantage of lignin is its antimicrobial activity. Although antimicrobial properties of the phenolic units of lignin are well documented [32], there has been some controversy in the literature whether lignin and lignin containing materials have antimicrobial activity. Erakovic et al. [28] have found no significant antimicrobial activity of films obtained by electrophoretic deposition from $1 \mathrm{wt} \%$ suspension of organosolv lignin in the presence of hydroxyapatite. Some antimicrobial activity was detected for sulphonated lignin [31]. However, no direct comparison of water insoluble lignin with sulphonated lignin is possible. Antimicrobial action of the latter may be ascribed to its surface active properties. Study of Dizhbite et al. [37] revealed antibacterial effect of kraft lignin and related it to the high activity as radical scavenger. Lignin-related compounds from pine cone are found to induce varieties of antiviral activity [38].

Composites and blends of lignin with cellulose [39], cellulose acetate [40], xanthan gum [41], PEG [42], PVA [43], PLA [44], PVP $[45,46]$ are known from the literature. Even though there may be only weak interaction between lignin and principal constituent, addition of lignin may offer advantages such as more control over water uptake [41] and improved mechanical properties [31,45]. Importance of conjugating lignin with polysaccharides for in vivo expression of various kinds of immunopotentiating activity is also reported [38]. These features may also have a beneficial effect with respect to biomedical applications.

Gelation by a reaction with crosslinkers is a common technique to obtain lignin aerogels. Gelation with resorcinol formaldehyde [47], phenol formaldehyde [48], tannin formaldehyde systems [49] and $\alpha, \omega$-diglycidyl ethers [50] are reported. To the best of our knowledge, ionic crosslinking of pure lignin or polymer blends containing lignin has not been reported. In this work a goal was set to use alginate as a "glue" for lignin. Presence of alginate allows the use of ionotropic gelation instead of chemical crosslinking.
Gelation of alginate induced by pressurized carbon dioxide was recently developed [51] and is used in this work to gel alginate-lignin mixtures. In processing of biomedical materials, $\mathrm{CO}_{2}$ induced gelation have certain advantages over internal and diffusion gelation methods: (i) carbon dioxide, being volatile acid in water media, can be recovered at post-processing stages; (ii) fast depressurization leads to macroporous foam-like hydrogels; (iii) bactericidal activity of pressurized $\mathrm{CO}_{2}$ simplifies preparation of food and medical materials [52]; and (iv) the process potentially allows to avoid ambient pressure solvent exchange and can be directly combined with subsequent supercritical drying $[51,53]$.

\section{Materials and methods}

\subsection{Chemicals}

Alginic acid sodium salt (suitable for immobilization of microorganisms grade, catalogue no. 71238) was obtained from Sigma Life science, Germany. Lignin was produced as described below (Section 2.2). Calcium carbonate (light, precipitated powder, particle size ca. $1 \mu \mathrm{m}$ ) was purchased from Magnesia GmbH, Germany. Sodium hydroxide (>99\%) and anhydrous ethanol $(99.9 \%)$ for the solvent exchange were purchased from Carl Roth $\mathrm{GmbH}$ and $\mathrm{H}$. Möller GmbH \& Co. KG, respectively. Carbon dioxide used for drying (99.9 mol\% purity) was procured from AGA Gas GmbH (Hamburg Germany). In case of in vitro cell culture studies, the chemicals used were of analytical reagent or tissue culture grade. Deionized water was used throughout the study.

\subsection{Starting solutions}

Lignin was obtained from wheat straw as described elsewhere $[50,54]$. This process was carried out by the biorefinery research group at the Institute of Thermal Separation Processes, Hamburg University of Technology (Germany). Briefly, wheat straw was fractioned by a hydrothermal pretreatment with liquid hot water at $473 \mathrm{~K}$ and $5 \mathrm{MPa}$ followed by an enzymatic hydrolysis step $\left(50^{\circ} \mathrm{C}\right.$ $\mathrm{pH}$ 5, Novozymes CTec2, 72 h). Water insoluble lignin was collected after the enzymatic cleavage. Lignin was washed with water and dried at $70^{\circ} \mathrm{C}$ for $50 \mathrm{~h} .3 \mathrm{wt} \%$ solution of lignin was prepared by mixing a certain amount of dried lignin with $1 \mathrm{M} \mathrm{NaOH}$ and overnight stirring.

$3 \mathrm{wt} \%$ sodium alginate solution was prepared by gentle overnight stirring of Na-Alg powder with water. After the preparation both solutions were bottled and stored at $5{ }^{\circ} \mathrm{C}$.

Calcium carbonate powder was dispersed in Na-Alg solution with a high speed homogenizer Ultra-turrax (IKA, Staufen, Germany). Then lignin solution was added to obtain desired alginate-to-lignin ratio: $2: 1,3: 1,4: 1$ or $5: 1(\mathrm{w} / \mathrm{w})$. Mixture was diluted with water to keep $1.5 \mathrm{wt} \%$ overall biopolymer concentration (alginate + lignin) and once again homogenized (Ultra-turrax) for $1 \mathrm{~min}$. Two crosslinking degrees $(q)$ were used: alginate-to$\mathrm{CaCO}_{3}$ of $1: 0.1825(\mathrm{w} / \mathrm{w})$ is referred as $q=1 . q=2$ corresponds to the doubled amount of $\mathrm{CaCO}_{3}$. Resulting suspension was filled into a standard 48 multiwell plate (BD Biosciences, USA) and subjected to $\mathrm{CO}_{2}$ induced gelation.

\section{3. $\mathrm{CO}_{2}$ induced gelation and hydrogel foaming}

Multiwell plates with $\mathrm{Na}-\mathrm{Alg} / \mathrm{lignin} / \mathrm{CaCO}_{3}$ mixture were placed into an autoclave and exposed to gaseous carbon dioxide at $4.5 \pm 0.5 \mathrm{MPa}$ and room temperature for $24 \mathrm{~h}$. The autoclave described elsewhere [55] was used for both gelation and supercritical drying. To study effect of the depressurization rate on macroporosity of the gels, pressure release was employed at $0.8 \mathrm{MPa} / \mathrm{min}$ and $3 \mathrm{MPa} / \mathrm{min}$. The gels were left in the air till 
formation of bubbles ceased, then washed with water and finally transferred into ethanol-water mixture to perform solvent exchange as described below.

\subsection{Solvent exchange and supercritical drying}

Hydrogels were immersed in grades of aqueous ethanol $(30,60$, 90 and $99.9 \mathrm{vol} . \%$ ) for $3 \mathrm{~h}$ at each ethanol concentration. The final solvent exchange was done twice or thrice before the hydrogels were supercritically dried. A density meter DMA 4500 (Anton Paar Company, Austria) was used to control completeness of the solvent exchange. Gels were wrapped in filter paper and placed into preheated autoclave $(318 \mathrm{~K})$. Supercritical drying was performed using the same autoclave as for gelation. The autoclave was sealed and $\mathrm{CO}_{2}$ was filled in by a compressor. Once $12 \pm 1 \mathrm{MPa}$ was reached, outlet was opened and constant flow $(0.2 \mathrm{~kg} / \mathrm{h})$ was set for $5 \mathrm{~h}$ such that 6-7 residence volumes of $\mathrm{CO}_{2}$ were used. Then system was depressurized in $30 \mathrm{~min}$ followed by cooling down to room temperature.

\subsection{Textural and morphological properties}

Bulk density of the samples was calculated as ratio of mass to volume. The length and diameter of the aerogels were measured with Vernier calipers. SEM pictures were taken by a Leo 1530 microscope (Carl Zeiss, Germany). Samples were sputtered with gold $(7 \mathrm{~nm})$. Pictures were taken at an accelerating voltage of $5 \mathrm{kV}$ and working distances in the range of $4.0-6.0 \mathrm{~mm}$. Surface area, pore volume and pore diameter were analyzed by nitrogen adsorption desorption techniques using Nova 3000e (Quantachrome Instruments, USA). Surface area was obtained from multipoint BET. Pore size distribution and volume of mesopores were calculated from desorption branch using $\mathrm{BJH}$ method. Porosity, interconnectivity and mean pore size in the macroporous range were evaluated by micro-CT using Scanco 20 equipment (Skyscan 1702, Belgium) with penetrative X-rays of $30 \mathrm{kV}$ and $167 \mu \mathrm{A}$, in high resolution mode with a pixel size of $14.71 \mu \mathrm{m}$ and $1.5 \mathrm{~s}$ of exposure time. A CT analyzer (v1.5.1.5, SkyScan) was used to visualize the samples and calculate the parameters from 2D aerogel structures. The analysis was done thrice within different regions of interest. Results are given as mean \pm standard deviation.

\subsection{Mechanical properties}

Compressive properties of the aerogels were measured using an INSTRON 5540 universal testing machine (Instron Int. Ltd, High Wycombe, UK) with a load cell of $1 \mathrm{kN}$. Compression tests were carried out at a crosshead of $2 \mathrm{~mm} / \mathrm{min}$, until a maximum deformation of $60 \%$. Young's modulus was calculated as the initial linear modulus on the stress-strain curves. The results are presented as the average of three experiments \pm standard deviation. In wet state, the samples were immersed for $10 \mathrm{~min}$ in PBS solution before compression tests.

\subsection{Water uptake}

Aerogel were placed into test tubes, filled with adequate amount of Tris- $\mathrm{HCl}$ buffer solution ( $\mathrm{pH} 7.4$ ) and placed in a water bath $\left(37^{\circ} \mathrm{C}, 60 \mathrm{rpm}\right)$. Weight of the swollen sample $w_{s}$ was measured after removing excess of the buffer with filter paper after 1, 3, 7 and 14 days. For each time point three parallel samples were measured and the water uptake $W U$ was calculated relative to the initial weight $w_{i}$ as follows:

$W U \%=\frac{w_{s}-w_{i}}{w_{i}} \times 100$.

\subsection{In vitro biological performance}

\subsubsection{Cell culture}

A mouse fibroblast-like cell line (L929 cell line, European Collection of Cell Cultures, UK) was maintained in DMEM (Sigma-Aldrich, Germany) supplemented with $10 \%$ heat-inactivated fetal bovine serum (Biochrom AG, Germany) and 1\% antibiotic-antimycotic solution (Gibco, UK). Cells were cultured in a humidified incubator at $37^{\circ} \mathrm{C}$ in a $5 \% \mathrm{CO}_{2}$ atmosphere.

\subsubsection{Indirect contact assay}

Aerogels extracts were prepared according ISO/EN 10993 in DMEM culture medium. L929 cells at a concentration $1.5 \times 10^{4} \mathrm{cell} / \mathrm{mL}$ were cultured in a 48 -well plate for $24 \mathrm{~h}$ at $37^{\circ} \mathrm{C}$. At this time, medium was replaced by aerogels extracts. Cell viability was evaluated by the MTS assay after $72 \mathrm{~h}$ of culture time.

\subsubsection{Direct contact assay}

Confluent L929 cells were harvested and seeded in the aerogel samples as follows. Samples were distributed in a 48-well cell culture plate. Samples were initially immersed in sterile PBS to swell the matrix. Later, PBS was removed and a drop $(20 \mu \mathrm{l})$ of a cell suspension with a concentration of $1.5 \times 10^{4}$ cells $/ \mathrm{ml}$ was added to each aerogel. These constructs were statically cultured for 1,3 and 7 days under the culture conditions of $37^{\circ} \mathrm{C}$ at $5 \% \mathrm{CO}_{2}$ in an incubator. Triplicates were used for each time point.

\subsubsection{MTS assay}

Cell viability of the aerogels was determined after the predetermined culture times by the MTS assay using the Cell Titer 96 AQueous One Solution Cell Proliferation Assay (Promega, USA) according to the manufacturer instructions. This assay is based on bioreduction of tetrazolium compound into water-soluble formazan derivative. The formazan absorbance which is directly proportional to the number of living cells was measured at $490 \mathrm{~nm}$ in a microplate reader (Synergie HT, Bio-Tek, USA).

In case of indirect contact, effect of the leachable released from the aerogels on cellular metabolism was evaluated by culturing L929 cells in the extracts obtained from aerogels. Latex was used as a negative control and TCP (tissue culture polystyrene) was used as a positive control. In direct contact assays the cell-scaffolds were transferred to a new culture plate in order to evaluate the presence of viable cells only on the surface of the aerogel. In this case, TCP was used as a positive control. All cytotoxicity screening tests were performed in three replicates and the results are presented as mean \pm standard deviation.

\subsection{Statistical analysis}

Statistical analysis of the data was conducted using IBM SPSS Statistics version 20 software. Shapiro-Wilk test was employed to evaluate the normality of the data sets. Once the results obtained did not follow a normal distribution, non-parametric tests, in particular, Kruskal-Wallis test was used to infer statistical significant differences. Differences between the groups with $p<0.05$ were considered to be statistically significant.

\section{Results and discussion}

Reports on alginate-based aerogels for biomedical application are limited. To the best of our knowledge, alginate aerogels were evaluated to date as drug delivery systems by Mehling et al. [56], García-González et al. [57]; Veronovski et al. [58,59]; Ulker and Erkey [60] and as bio-superadsorbents by Mallepally et al. [61]. 


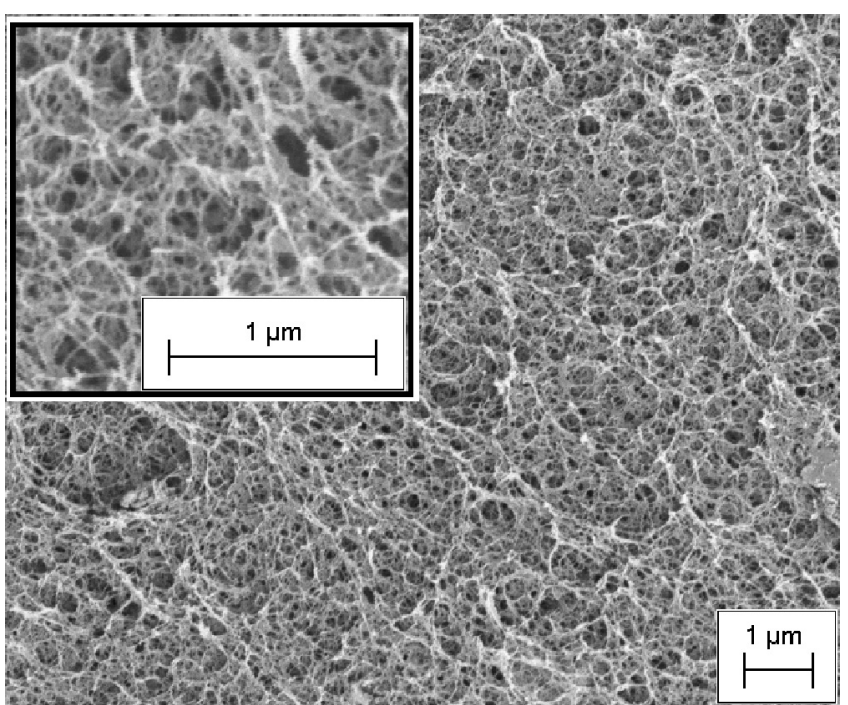

Fig. 1. SEM structure of alginate-lignin aerogel (alginate/lignin ratio $4: 1(\mathrm{w} / \mathrm{w})$, $q=2$ ).

Production of aerogels with controlled pore size and dual pore size distribution still remains a challenge and restrains aerogels from filling a niche in regenerative medicine where macroporosity of the scaffold is of concern. As pointed out by Reverchon et al. [3], it is very difficult to obtain the coexistence of the macro and microstructural characteristics within one scaffold. Various techniques have been proposed to address this issue: addition of solid/liquid porogen with subsequent leaching [3]; emulsion templating $[62,63]$ including supercritical carbon dioxide as a dispersed phase [64,65]; in situ generation of gas bubbles confined in the gel [63] or rapid expansion of a gas dissolved in the gel (see below). In this report gelation induced by pressurized $\mathrm{CO}_{2}$ with subsequent foaming was performed to create macroporous aerogels.

\section{1. $\mathrm{CO}_{2}$ induced gelation}

Solubility of carbon dioxide in water increases with rising pressure along with lowering of $\mathrm{pH}$ down to 3 [66]. The drop in $\mathrm{pH}$ causes in turn an increase in solubility of calcium carbonate along with the release of calcium ions. At conditions used in this study for gelation (298 $\mathrm{K}$ and $4.5 \mathrm{MPa}$ ), $\mathrm{CaCO}_{3}$ solubility is much larger (ca. $2.8 \mathrm{~g} / \mathrm{L},[67])$ than at ambient conditions $(0.006-0.01 \mathrm{~g} / \mathrm{L},[68]$ ) so considerable amount of $\mathrm{Ca}^{2+}$ ions is available for the reaction with alginate. To support that $\mathrm{Ca}^{2+}$ ions act as crosslinker a blank experiment was performed. It showed that alginate does not form a gel in the absence of $\mathrm{CaCO}_{3}$. Experiments in a tilting viewing cell showed no noticeable increase in viscosity neither for Na-Alg solution alone nor for $\mathrm{Na}-\mathrm{Alg} / \mathrm{lignin}$ mixture. These findings can be attributed to moderate $\mathrm{pH}$ change: in pure $\mathrm{CO}_{2} /$ water system at $25^{\circ} \mathrm{C} \mathrm{pH}$ approaches value of around 3 and remains constant above $3 \mathrm{MPa}$ [69]. Apparently, this $\mathrm{pH}$ is not low enough to form a stable acid alginate gel ( $\mathrm{p} K_{\mathrm{a}}$ of $\mathrm{M}$ and $\mathrm{G}$ units in the range of 3.4-3.7, [70]). Moreover, sodium hydroxide introduced with lignin solution reacts with $\mathrm{CO}_{2}$ yielding bicarbonate, which possesses buffer properties: bicarbonate buffer at $5 \mathrm{MPa} \mathrm{CO}_{2}$ pressure is able to maintain $\mathrm{pH}$ around 6-7 (only drop $0.5-1.0 \mathrm{pH}$ units compare to ambient conditions, [71]). In this regard, this gelation method can be classified as the internal setting method exploiting acidic properties of $\mathrm{CO}_{2}$-water mixture.

In this study the $\mathrm{CO}_{2}$ induced gelation method was extended over polymer compositions. SEM analysis of aerogels showed the net-like structure, which is typical to alginate aerogels (Fig. 1). Visual inspection of hydrogels and SEM revealed no sign of lignin inclusions. Some authors have found that lignin has limited compatibility with other biopolymers, e.g. with cellulose [39] and xanthan gum [41]. These findings support rather interpenetrating than co-crosslinking structure of the hybrid network. Rudaz [40] have prepared hybrid cellulose-lignin hydrogels and noticed that lignin can be washed out from the hydrogels during the solvent exchange due to weak cellulose-lignin interaction. This in turn led to the increase in porosity of cellulose aerogels since lignin acted as a porogen. In this study an opposite trend was found. As lignin concentration increases the BJH pore volume decreases (see Fig. 3). However, it was not possible to obtain stable hydrogels with lower alginate-to-lignin ratio than 2:1 (w/w). Additional experiments with pure lignin with and without $\mathrm{Ca}^{2+}$ resulted in lignin precipitation demonstrating that lignin of itself is unable to form a gel at this condition. Taking into account the high affinity of $\mathrm{Ca}^{2+}$ to lignin [72], we suppose that $\mathrm{OH}$-groups of lignin may participate in the formation of egg-box junctions, but only to certain extent. Partial substitution of alginate $\mathrm{COO}^{-}$groups with phenolic $\mathrm{OH}$-groups of lignin in the egg-box junctions may explain the absence of lignin inclusions in the aerogels.

\subsection{Foaming of hydrogels}

Foaming of hydrogels is a well-known process exemplified by cellulose [73], chitin [74] and gelatin [75]. However, to the best of our knowledge, combination of both gelation and foaming into a one-pot approach has not been reported. Moreover, such a combination opens up an inviting prospect to realize all steps of aerogel processing (gelation, foaming, solvent exchange and supercritical drying and loading) under carbon dioxide pressure as an integrated process [51,53].

For the purposes of tissue engineering scaffolds the important conclusion is that $\mathrm{CO}_{2}$ induced gelation should be coupled with fast pressure release to obtain macroporosity. Indeed, our results indicate great impact of the depressurization rate: $3 \mathrm{MPa} / \mathrm{min}$ favors formation of numerous pores of approximately $200 \mu \mathrm{m}$ in size, whereas slow pressure release $(0.8 \mathrm{MPa} / \mathrm{min})$ led to significantly low porosity with two-fold larger pores (Fig. 2). Very slow depressurization at $0.02 \mathrm{MPa} / \mathrm{min}$ gave no detectable macroporosity (data not shown).

Table 1 summarizes results of micro-CT assessment for the aerogels produced through preceding foaming. Foaming allowed to introduce macropores in the range of $200-450 \mu \mathrm{m}$. Aerogels foamed at higher depressurization rate demonstrate two-fold increase in overall macroporosity along with almost two-fold decrease in mean pore size. This decrease in pore size is however well above a minimal size (38-63 $\mu \mathrm{m})$, which allows cell to grow and proliferate [76]. These results indicate that $\mathrm{CO}_{2}$ induced gelation followed by hydrogel foaming seems to be an efficient method to introduce macroporosity into hydrogels and aerogels, which are intrinsically micro- and mesoporous.

In the context of this study it is interesting to adduce results from Floren et al. [77] for silk protein hydrogels prepared under high pressure $\mathrm{CO}_{2}(0.5-15 \mathrm{MPa})$. In this work acidification of silk fibroin aqueous solution by pressurized $\mathrm{CO}_{2}$ led to the formation of stable hydrogel through the development of extensive $\beta$-sheet structures. The results of Floren et al. indicate that protein hydrogels prepared under $\mathrm{CO}_{2}$ pressure followed by slow depressurization (0.02-0.5 MPa/min) display distinctly more homogeneous pore structure compare to fibroin hydrogels acidified by citric acid at ambient conditions [77]. This clearly shows that carbon dioxide induced gelation, not followed by fast depressurization, leads to more compact hydrogels compare to ambient conditions. This conclusion is in agreement with observations made by Annabi et al. [78]. Elastin-based hydrogels produced in pressurized $\mathrm{CO}_{2}$ were found to be stiffer (in terms of compression modulus) than those 

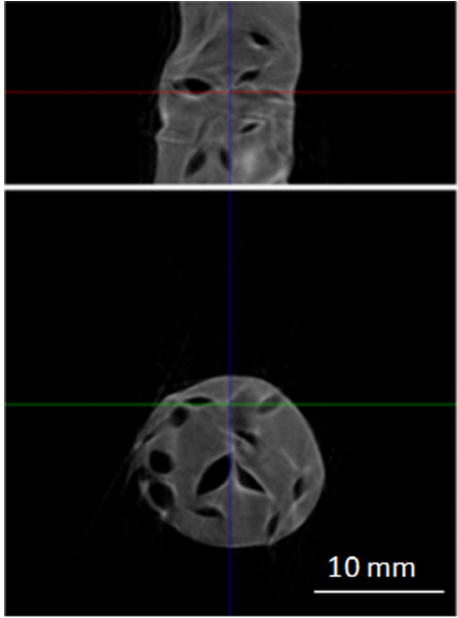

(a)

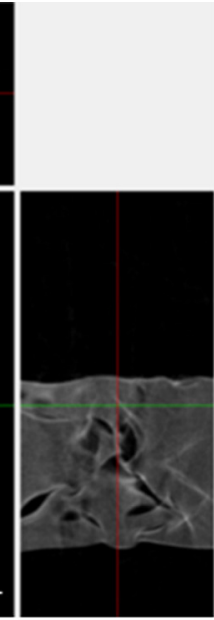

Fig. 2. Micro-CT image of alginate-lignin aerogels produced depressurization rate of $0.8 \mathrm{MPa} / \mathrm{min}$ (a) and $3 \mathrm{MPa} / \mathrm{min}$ (b).
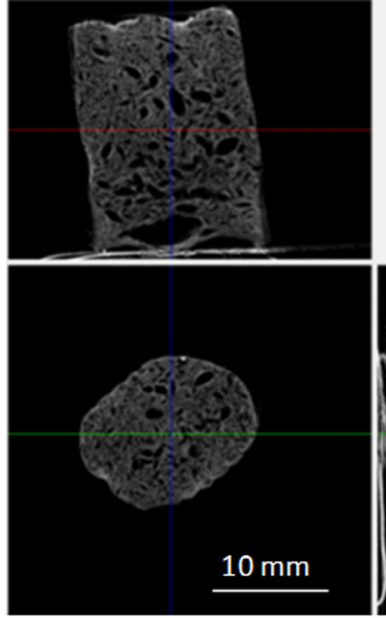

(b)

Table 1

Results of micro-CT analysis for aerogels foamed at different depressurization rates.

\begin{tabular}{lclc}
\hline Depressurization rate, $\mathrm{MPa} / \mathrm{min}$ & Porosity, \% & Mean pore size, $\mu \mathrm{m}$ & Interconnectivity, \% \\
\hline 0.8 & $14.28 \pm 0.96$ & $423 \pm 7$ & $27.6 \pm 4.6$ \\
3 & $31.3 \pm 1.9$ & $220 \pm 18$ & $33.2 \pm 8.3$ \\
\hline
\end{tabular}

produced at atmospheric conditions. In addition, another study revealed that gelation at high pressure reduces the pore size of the hydrogels [79]. One possible explanation for these findings is that high pressure $\mathrm{CO}_{2}$ facilitates coacervation of the polymer leading to densification of the polymer junctions. We can speculate that a similar phenomenon allowed us to prepare pure alginate hydrogels from Na-Alg with concentration as low as $0.25 \mathrm{wt} \%$, whereas conventional methods led to unsatisfactory results [51].

\subsection{Textural properties}

To study the effect of lignin concentration on the textural properties of the aerogels, alginate-to-lignin ratios of $2: 1,3: 1,4: 1$ or $5: 1(\mathrm{w} / \mathrm{w})$ were studied keeping overall biopolymer concentration at $1.5 \mathrm{wt} \%$. The effect of the crosslinking degree, $q$, on textural properties was also studied at two different levels (Fig. 3a and b). All alginate-lignin aerogels showed bulk densities in the range $0.03-0.07 \mathrm{~g} / \mathrm{cm}^{3}$. No clear trend was observed with the crosslinking degree or the lignin concentration. Conversion of hydrogels into aerogels implies shrinkage of certain extent [57]. Overall

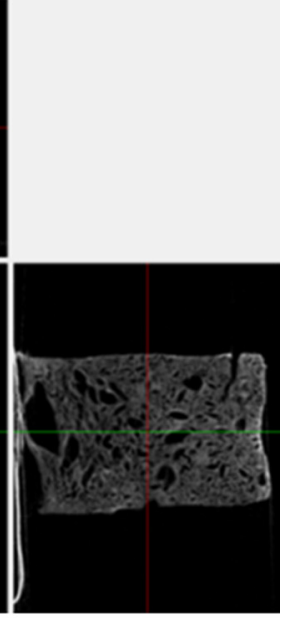

$33.2 \pm 8.3$ linear shrinkage caused by solvent exchange and supercritical drying was in the range of $20-35 \%$ across all samples. Despite the pronounced shrinkage all aerogels remained cylindrical shape and showed quite high surface area compare to the state of the art (150-600 $\mathrm{m}^{2} / \mathrm{g}$ and up to $450 \mathrm{~m}^{2} / \mathrm{g}$ for alginate and lignin aerogels, respectively, [49,57]). Doubled crosslinker amount $(q=2)$ leads to moderate reduction in surface area (Fig. 3a), whereas reduction in pore volume is more pronounced (Fig. 3b). At $q=2$, lignin concentration does not exert much influence on the surface area. In other words, higher crosslinking degree results in more compact aerogel structures, whereas $q=1$ and lower crosslinking degree led to soft and difficult-to-handle hydrogels. Moreover, foaming of a less crosslinked gel often resulted in its disruption. In search of a compromise between possibly high lignin concentration, good textural properties (high surface area, pore volume) and ability to perform foaming the crosslinking degree was kept constant at 2 and alginate-to-lignin ratio at $4: 1(\mathrm{w} / \mathrm{w})$. All further in vitro studies were performed with this formulation, which exhibited the density of $0.07 \pm 0.01 \mathrm{~g} / \mathrm{cm}^{3}$ and surface area of $382 \mathrm{~m}^{2} / \mathrm{g}$.

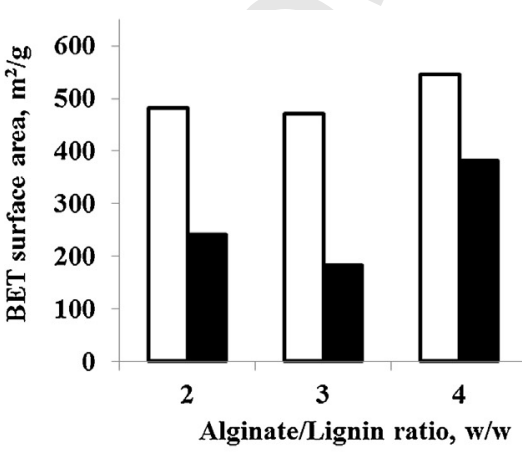

(a)

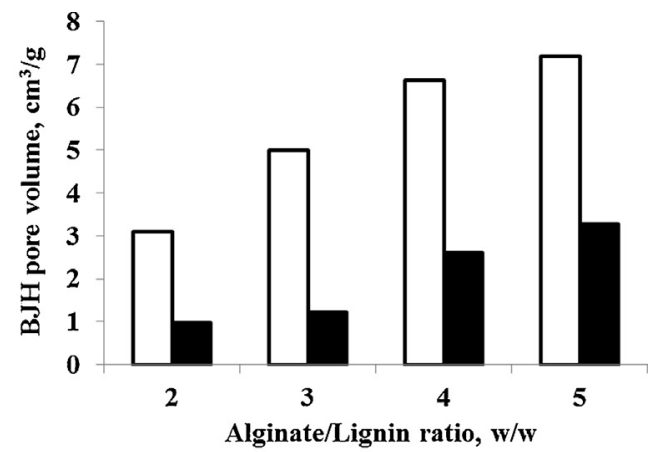

(b)

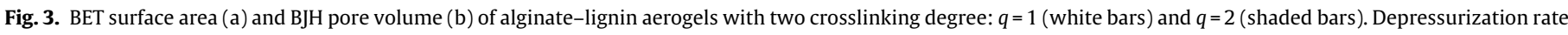
is $0.8 \mathrm{MPa} / \mathrm{min}$. 


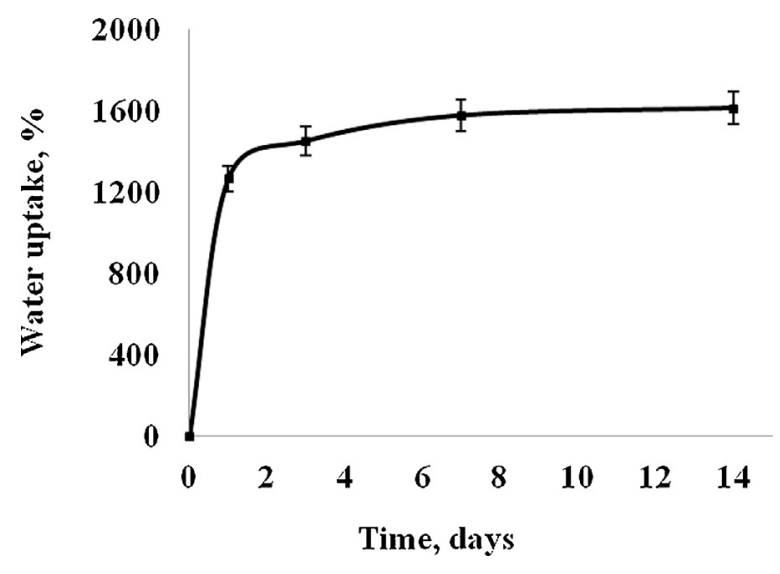

Fig. 4. Fluid uptake kinetics in Tris- $\mathrm{HCl}$ buffer $\left(\mathrm{pH} \mathrm{7.4)}\right.$ at $37^{\circ} \mathrm{C}$ and $60 \mathrm{rpm}$.

\subsection{Water uptake}

Water uptake study was done with alginate-lignin aerogels in Tris- $\mathrm{HCl}$ buffer. The latter was chosen instead of commonly used PBS due to its lower affinity to calcium ions. Phosphate ions presented in PBS leads to fast dissolution of the alginate materials [80] so that water uptake may be distorted due to fast calcium leakage [81]. The water uptake gradually increased from day 1 to day 14 and reached a plateau after about 1 week (Fig. 4). Compared to pure alginate aerogels and starch-alginate hybrids [82] it was found that lignin slows down the water uptake kinetics, consistent with its hydrophobic nature. Equilibrium water uptake of alginatebased materials presented in the literature varies in the wide range from 30 to 35,000\% [83-85]. On account of vast variety of production methods a direct comparison is difficult. Kulkarni et al. [84] have found similar water uptake for chemically crosslinked alginate, but with much faster kinetics (equilibrium reached in 2-4 h). It was noticed $[81,85]$ that almost no swelling happened upon contact with Tris- $\mathrm{HCl}$ buffer due to the lack of specific interaction between buffer and Ca-crosslinked alginate. Our results however show that alginate-lignin aerogels are able to uptake up to $1613 \%$ of Tris- $\mathrm{HCl}$ buffer. Swelling of the material was also noticed during the study. Although detailed mechanism of water uptake needs to be elucidated it is clear that not only pore filling contributes into the equilibrium uptake but also the swelling of the matrix.

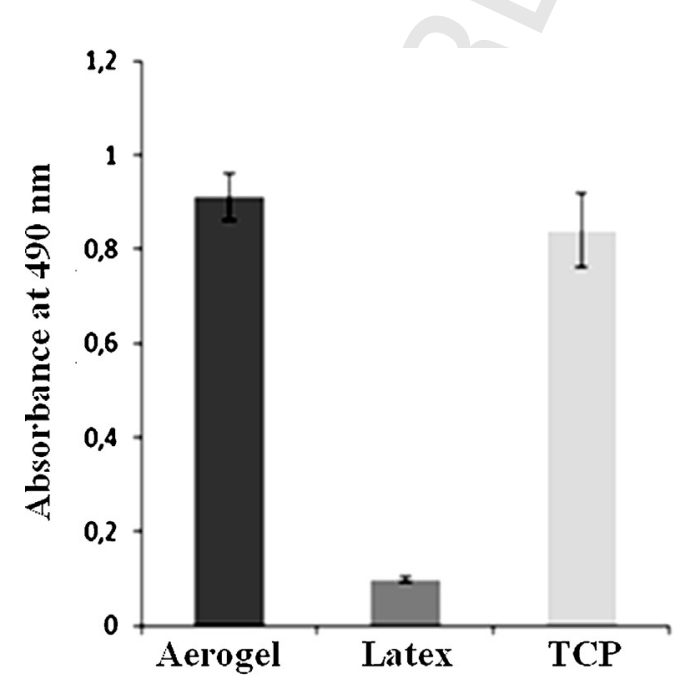

(a)

Table 2

Young modulus of alginate-lignin aerogels in the dry and wet states.

\begin{tabular}{ll}
\hline $\begin{array}{l}\text { Sample; rate of } \\
\text { depressurization, } \mathrm{MPa} / \mathrm{min}\end{array}$ & $\begin{array}{l}\text { Young's modulus, } \\
\mathrm{MPa}\end{array}$ \\
\hline Alginate-lignin dry; 0.8 & $1.36 \pm 0.24$ \\
Alginate-lignin dry; 3 & $0.38 \pm 0.05$ \\
Alginate-lignin wet; 0.8 & $0.05 \pm 0.02$ \\
Alginate-lignin wet; 3 & $0.02 \pm 0.01$ \\
\hline
\end{tabular}

\subsection{Mechanical properties}

In the context of tissue engineering applications, mechanical properties are an important characteristic. The mechanical response of the alginate-lignin aerogels prepared at two different depressurization rates were evaluated in the compression mode. Table 2 compares Young's modulus of dry and wet aerogels. As can be seen from this data alginate-lignin aerogels can be classified as materials with low stiffness both in dry and wet states. Their Young moduli are in the range of granulation and fibrous tissues [86]. It was also found that Young's modulus is affected by the depressurization rate: the value was three times lower for the aerogel foamed at $3 \mathrm{MPa} / \mathrm{min}$ than at $0.8 \mathrm{MPa} / \mathrm{min}$, whereas wetting makes aerogels almost insensitive to the rate of depressurization.

Due to various compression conditions reported in the literature (compression rate, range of strain for Young's modulus) and variation in aerogel densities a comprehensive comparison is infeasible. Native silica aerogels are brittle and break at small tensile strains [2]. Viggiano and Schiraldi [87] have reported the compressive modulus of $1.78 \mathrm{MPa}$ for a cryogel composed of alginate and lignin $(1: 1, w / w$, ratio with $5 \%$ overall solid content). This result is close to our results for dry aerogels. Alginate-lignin aerogels reported here demonstrate compressibility and become flexible when compressed, similar to pure alginate aerogels produced by $\mathrm{CO}_{2}$ induced gelation [51]. This behavior is rather unusual for biopolymer aerogels and has mainly been observed for polymer crosslinked silica aerogels, e.g. isocyanate-coated silica aerogels [2].

\subsection{In vitro biological performance}

In a first approach the cytotoxicity of the samples prepared was evaluated. Indirect studies were conducted to check the effect of the leachables of the matrices on cells cultured in a tissue plate.

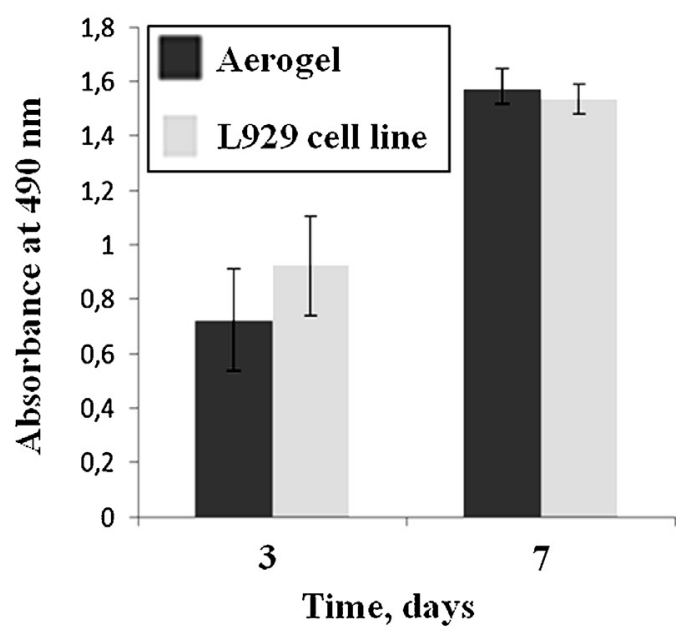

(b)

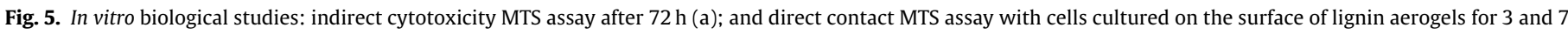
days (b). 
As negative control we used latex rubber and as positive control cells cultured in DMEM culture media. Cytotoxicity screening by indirect contact assay studies revealed that alginate-lignin aerogels did not show any evidence of toxic effects of the leachables over the fibroblast like L929 cells (Fig. 5a). Cell viability after $72 \mathrm{~h}$ for alginate-lignin was comparable to TCP, whereas latex showed clear cytotoxic effect. These results demonstrate that despite the phenolic nature of lignin, it can be used as a material for biomedical and pharmaceutical applications, at least in the concentration range used for aerogel preparation.

The main result of this indirect study is that alginate-lignin aerogel does not hinder cell growth and thus can be recognized as non-cytotoxic material. Cell adhesion tests revealed that cells are able to adhere on the surface of the materials and the metabolic activity has increased from day 3 to day 7 , comparable to TCP results (Fig. 5b).

These results give an account that the alginate-lignin aerogel demonstrate no cytotoxicity and good cell adhesion properties, at least in the range of lignin concentration studied. This clearly indifor further in vitro and in vivo testing.

\section{Conclusions}

The present work deals with the production of alginate-lignin aerogels using $\mathrm{CO}_{2}$ induced gelation followed by solvent exchange ifier to liberate $\mathrm{Ca}^{2+}$ ions for the crosslinking of alginate-lignin mixture. Foaming by rapid expansion of carbon dioxide can be readily implemented to introduce macroporosity in the aerogels. Foaming procedure is free of templating agents and shown to be an effective way to introduce macropores of few hundred microns into hydrogels and subsequently aerogels. Despite the pronounced shrinkage, aerogels produced by $\mathrm{CO}_{2}$ induced gelation followed by foaming demonstrate low density and good textural properties both at meso and macroscale. Apart from readily available foaming there are several additional advantages in using pressurized $\mathrm{CO}_{2}$ to induce gelation. First, carbon dioxide strengthened the hydrogel, whereas hydrogels formed from the same formulation at ambient conditions are more soft and often do not preserve the shape. Second, wide range of polymers can be mixed with alginate leading to hybrid hydrogels with modified properties. Third, the use of carbon dioxide as a volatile acidifier, allows for efficient recovery of $\mathrm{CO}_{2}$ at post-processing stages. Finally, the process can be directly combined with subsequent supercritical drying into a one-pot approach. In this work we have proven the feasibility of alginate-lignin aerogels to be used in a tissue engineering perspective.

The alginate-lignin aerogels present textural and morphological properties suitable for tissue engineering applications. Furthermore they have high equilibrium water uptake. In terms of Young's modulus studied aerogels can be classified as material with low stiffness both in dry and wet states. In vitro cytotoxicity screening has demonstrated that lignin does not compromise cell viability and it has been shown that alginate-lignin aerogels possess good cell adhesion properties prompting possible further in vitro and in vivo assessment.

\section{Acknowledgements}

The research leading to these results has received funding from Fundação da Ciência e Tecnologia (FCT) through the project ENIGMA - PTDC/EQU-EPR/121491/2010, and from the European Union's Seventh Framework Programme (FP7/2007-2013) under cates that lignin-containing aerogels can be viewed as candidates and supercritical drying. Pressurized carbon dioxide acts as an acidgrant agreement no. REGPOT-CT2012-316331-POLARIS and from
Project "Novel smart and biomimetic materials for innovative regenerative medicine approaches (Ref.: RL1 - ABMR - NORTE01-0124-FEDER-000016)" cofinanced by North Portugal Regional Operational Programme (ON.2-O Novo Norte), under the National Strategic Reference Framework (NSRF), through the European Regional Development Fund (ERDF) and FEDER.

Authors are grateful for financial support from Fundação da Ciência e Tecnologia (FCT) through the grant BIM/PTDC/EQUEPR/121491/2010/ENIGMA, bilateral cooperation project FCTDAAD 57036335, and from DFG (projects SM 82/8-1 and SM 82/8-2). Pavel Gurikov acknowledges DAAD for supporting him through a postdoctoral fellowship.

\section{References}

[1] A.R.C. Duarte, J.F. Mano, R.L. Reis, Perspectives on: supercritical fluid technology for 3D tissue engineering scaffold applications, J. Bioactive and Compatible Polymers 24 (2009) 385-400.

[2] M.A. Aegerter, N. Leventis, M.M. Koebel (Eds.), Aerogels Handbook, Springer, 2011.

[3] E. Reverchon, S. Cardea, C. Rapuano, A new supercritical fluid-based process to produce scaffolds for tissue replacement, J. Supercritical Fluids 45 (2008) 365-373.

[4] K. Rinki, P.K. Dutta, A.J. Hunt, J.H. Clark, D.J. Macquarrie, Preparation of chitosan based scaffolds using supercritical carbon dioxide, Macromolecular Symposia 277 (2009) 36-42.

[5] S. Cardea, P. Pisanti, E. Reverchon, Generation of chitosan nanoporous structures for tissue engineering applications using a supercritical fluid assisted process, J. Supercritical Fluids 54 (2010) 290-295

[6] R. Kumari, P.K. Dutta, Physicochemical and biological activity study of genipincrosslinked chitosan scaffolds prepared by using supercritical carbon dioxide for tissue engineering applications, International J. Biological Macromolecules 46 (2010) 261-266.

[7] F. Sabri, J.D. Boughter Jr., D. Gerth, O. Skalli, T.-C.N. Phung, G.-R.M. Tamula, et al., Histological evaluation of the biocompatibility of polyurea crosslinked silica aerogel implants in a rat model: a pilot study, PLoS ONE 7 (2012) e50686.

[8] F. Sabri, J.A. Cole, M.C. Scarbrough, N. Leventis, Investigation of polyureacrosslinked silica aerogels as a neuronal scaffold: a pilot study, PLoS ONE 7 (2012) e33242

[9] F. Sabri, J. Cole, M. Cody Scarbrough, N. Leventis, Investigation of crosslinked silica aerogels for implant applications, in: Biomedical Sciences and Engineering Conference (BSEC), 2011, 2011, pp. 1-3.

[10] H.H. Tønnesen, J. Karlsen, Alginate in drug delivery systems, Drug Development and Industrial Pharmacy 28 (2002) 621-630.

[11] C.K. Kuo, P.X. Ma, Ionically crosslinked alginate hydrogels as scaffolds for tissue engineering: Part 1 . Structure, gelation rate and mechanical properties, Biomaterials 22 (2001) 511-521.

[12] I. Machida-Sano, Y. Matsuda, H. Namiki, A novel harvesting method for cultured cells using iron-cross-linked alginate films as culture substrates, Biotechnology and Applied Biochemistry 55 (2010) 1-8.

[13] K.Y. Lee, D.J. Mooney, Hydrogels for tissue engineering, Chemical Reviews 101 (2001) 1869-1880.

[14] I. Donati, S. Paoletti, Material properties of alginates, in: B.H.A. Rehm (Ed.), Alginates: Biology and Applications, Springer, Berlin Heidelberg, 2009, pp. 1-53.

[15] S.L. Holdt, S. Kraan, Bioactive compounds in seaweed: functional food applications and legislation, J. Applied Phycology 23 (2011) 543-597.

[16] S. Pallerla, R.P. Chambers, Characterization of a Ca-alginate-immobilized Trametes versicolor bioreactor for decolorization and AOX reduction of paper mill effluents, Bioresource Technology 60 (1997) 1-8.

[17] W. Bohrn, R. Lewis, W. Moggio, Alginate gel particle inks or dye liquors for imparting color to textiles, US Patent $4713084 \mathrm{~A}$.

[18] A.D. Augst, H.J. Kong, D.J. Mooney, Alginate hydrogels as biomaterials, Macromolecular Bioscience 6 (2006) 623-633.

[19] W.R. Gombotz, S.F. Wee, Protein release from alginate matrices, Advanced Drug Delivery Reviews 64 (2012) 194-205.

[20] J.A. Rowley, G. Madlambayan, D.J. Mooney, Alginate hydrogels as synthetic extracellular matrix materials, Biomaterials 20 (1999) 45-53.

[21] N.G. Genes, J.A. Rowley, D.J. Mooney, L.J. Bonassar, Effect of substrate mechanics on chondrocyte adhesion to modified alginate surfaces, Archives of Biochemistry and Biophysics 422 (2004) 161-167.

[22] E. Alsberg, K.W. Anderson, A. Albeiruti, R.T. Franceschi, D.J. Mooney, Cellinteractive alginate hydrogels for bone tissue engineering, J. Dental Research 80 (2001) 2025-2029.

[23] N. Iwasaki, S.-T. Yamane, T. Majima, Y. Kasahara, A. Minami, K. Harada, et al., Feasibility of polysaccharide hybrid materials for scaffolds in cartilage tissue engineering: evaluation of chondrocyte adhesion to polyion complex fibers prepared from alginate and chitosan, Biomacromolecules 5 (2004) 828-833.

[24] M. Rinaudo, Main properties and current applications of some polysaccharides as biomaterials, Polymer International 57 (2008) 397-430.

\section{5 \\ 55 \\ 55

$$
6
$$$$
\begin{aligned}
& 62 \\
& 625 \\
& 62
\end{aligned}
$$ 
[25] H.-R. Lin, Y.-J. Yeh, Porous alginate/hydroxyapatite composite scaffolds for bone tissue engineering: preparation, characterization, and in vitro studies, J. Biomedical Materials Research Part B: Applied Biomaterials 71B (2004) 52-65.

[26] K. Smetana Jr., Cell biology of hydrogels, Biomaterials 14 (1993) 1046-1050.

[27] H.S. Mansur, A.A.P. Mansur, S.M.C.M. Bicallho, Lignin-hydroxyapatite/ tricalcium phosphate biocomposites: SEM/EDX and FTIR characterization, Key Engineering Materials 284-286 (2005) 745-748.

[28] S. Erakovic, A. Jankovic, G.C.P. Tsui, C.-Y. Tang, V. Miskovic-Stankovic, T. Stevanovic, Novel bioactive antimicrobial lignin containing coatings on titanium obtained by electrophoretic deposition, International J. Molecular Sciences 15 (2014) 12294-12322.

[29] H.D. Greve, A.-M.D.M. Vestweber, A composition for use as a laxative, Patent DE102006017672, p. A1.

[30] T. Honeycutt, Decreasing allergenicity of natural latex rubber prior to vulcanization, Patent US7056970, p. B2.

[31] R. Núñez-Flores, B. Giménez, F. Fernández-Martín, M.E. López-Caballero, M.P. Montero, M.C. Gómez-Guillén, Role of lignosulphonate in properties of fish gelatin films, Food Hydrocolloids 27 (2012) 60-71.

[32] B. Baurhoo, C.A. Ruiz-Feria, X. Zhao, Purified lignin: nutritional and health impacts on farm animals-a review, Animal Feed Science and Technology 144 (2008) 175-184.

[33] K.S. Khitrin, S.L. Fuks, S.V. Khitrin, S.A. Kazienkov, D.S. Meteleva, Lignin utilization options and methods, Russian J. General Chemistry 82 (2012) 977-984.

[34] P. Azadi, O.R. Inderwildi, R. Farnood, D.A. King, Liquid fuels, hydrogen and chemicals from lignin: a critical review, Renewable and Sustainable Energy Reviews 21 (2013) 506-523.

[35] V. Ugartondo, M. Mitjans, M.P. Vinardell, Comparative antioxidant and cytotoxic effects of lignins from different sources, Bioresource Technology 99(2008) 6683-6687.

[36] C. Frangville, M. Rutkevičius, A.P. Richter, O.D. Velev, S.D. Stoyanov, V.N. Paunov, Fabrication of environmentally biodegradable lignin nanoparticles, ChemPhysChem 13 (2012) 4235-4243.

[37] T. Dizhbite, G. Telysheva, V. Jurkjane, U. Viesturs, Characterization of the radical scavenging activity of lignins-natural antioxidants, Bioresource Technology 95 (2004) 309-317.

[38] H. Sakagami, Y. Kawazoe, N. Komatsu, A. Simpson, M. Nonoyama, K. Konno, et al., Antitumor, antiviral and immunopotentiating activities of pine cone extracts: potential medicinal efficacy of natural and synthetic lignin-related materials (review), Anticancer Research 11 (1991) 881-888.

[39] R. Sescousse, A. Smacchia, T. Budtova, Influence of lignin on cellulose- $\mathrm{NaOH}$-water mixtures properties and on aerocellulose morphology, Cellulose 17 (2010) 1137-1146.

[40] C. Rudaz, Cellulose and Pectin Aerogels Towards Their Nano-structuration, MINES ParisTech, 2013.

[41] I.E. Raschip, C. Vasile, D. Ciolacu, G. Cazacu, Semi-interpenetrating polymer networks containing polysaccharides. I. Xanthan/lignin networks, High Performance Polymers 19 (2007) 603-620.

[42] J.F. Kadla, S. Kubo, Miscibility and hydrogen bonding in blends of poly(ethylene oxide) and kraft lignin, Macromolecules 36 (2003) 7803-7811

[43] S. Kubo, J.F. Kadla, The formation of strong intermolecular interactions in immiscible blends of poly(vinyl alcohol) (PVA) and lignin, Biomacromolecules 4 (2003) 561-567.

[44] J. Li, Y. He, Y. Inoue, Thermal and mechanical properties of biodegradable blends of poly(L-lactic acid) and lignin, Polymer International 52 (2003) 949-955.

[45] C. Liu, C. Xiao, H. Liang, Properties and structure of PVP-lignin blend films, J. Applied Polymer Science 95 (2005) 1405-1411.

[46] G. Cunxiu, C. Donghua, T. Wanjun, L. Changhua, Properties and thermal degradation study of blend films with poly(4-vinylpyridine) and lignin, J. Applied Polymer Science 97 (2005) 1875-1879.

[47] F. Chen, M. Xu, L. Wang, J. Li, Preparation and characterization of organic aerogels by the lignin-resorcinol-formaldehyde copolymer, Bioresources 6 (2011) $1262-1272$.

[48] L.I. Grishechko, G. Amaral-Labat, A. Szczurek, V. Fierro, B.N. Kuznetsov, A. Celzard, Lignin-phenol-formaldehyde aerogels and cryogels, Microporous and Mesoporous Materials 168 (2013) 19-29.

[49] L.I. Grishechko, G. Amaral-Labat, A. Szczurek, V. Fierro, B.N. Kuznetsov, A. Pizzi, et al., New tannin-lignin aerogels, Industrial Crops and Products 41 (2013) 347-355.

[50] L. Perez-Cantu, F. Liebner, I. Smirnova, Preparation of aerogels from wheat straw lignin by cross-linking with oligo(alkylene glycol)- $\alpha, \omega$-diglycidyl ethers, Microporous and Mesoporous Materials 195 (2014) 303-310.

[51] P. Gurikov, S. Raman, D. Weinrich, M. Fricke, I. Smirnova, A novel approach to alginate aerogels: carbon dioxide induced gelation, RSC Advances (2014), http://dx.doi.org/10.1039/C4RA14653K (accepted for publication).

[52] L. Garcia-Gonzalez, A.H. Geeraerd, S. Spilimbergo, K. Elst, L. Van Ginneken, J. Debevere, et al., High pressure carbon dioxide inactivation of microorganisms in foods: the past, the present and the future, International J. Food Microbiology 117 (2007) 1-28.

[53] S.P. Raman, P. Gurikov, I. Smirnova, An integrated approach towards biopolymer aerogels using high pressure solvent exchange, in: Proceeding of the 14th European Meeting on Supercritical Fluids, Marseille, 2014.

[54] T. Ingram, K. Wörmeyer, J.C.I. Lima, V. Bockemühl, G. Antranikian, G. Brunner, et al., Comparison of different pretreatment methods for lignocellulosic materials. Part I: Conversion of rye straw to valuable products, Bioresource Technology 102 (2011) 5221-5228.
[55] I. Smirnova, J. Mamic, W. Arlt, Adsorption of drugs on silica aerogels, Langmuir 19 (2003) 8521-8525.

[56] T. Mehling, I. Smirnova, U. Guenther, R.H.H. Neubert, Polysaccharide-based aerogels as drug carriers, J. Non-Crystalline Solids 355 (2009) 2472-2479.

[57] C.A. García-González, M. Alnaief, I. Smirnova, Polysaccharide-based aerogels-promising biodegradable carriers for drug delivery systems, Carbohydrate Polymers 86 (2011) 1425-1438.

[58] A. Veronovski, Z. Novak, Z. Knez, Synthesis and use of organic biodegradable aerogels as drug carriers, J. Biomaterials Science. Polymer Edition 23 (2012) 873-886.

[59] A. Veronovski, Ž. Knez, Z. Novak, Preparation of multi-membrane alginate aerogels used for drug delivery, J. Supercritical Fluids 79 (2013) 209-215.

[60] Z. Ulker, C. Erkey, An emerging platform for drug delivery: aerogel based systems, J. Controlled Release 177 (2014) 51-63.

[61] R.R. Mallepally, I. Bernard, M.A. Marin, K.R. Ward, M.A. McHugh, Superabsorbent alginate aerogels, J. Supercritical Fluids 79 (2013) 202-208.

[62] F.J. Zhang, G.X. Cheng, Z. Gao, C.P. Li, Preparation of porous calcium alginate membranes/microspheres via an emulsion templating method, Macromolecular Materials and Engineering 291 (2006) 485-492.

[63] A. Barbetta, E. Barigelli, M. Dentini, Porous alginate hydrogels: synthetic methods for tailoring the porous texture, Biomacromolecules 10 (2009) 2328-2337.

[64] S. Partap, I. Rehman, J.R. Jones, J.A. Darr, Supercritical carbon dioxide in water emulsion-templated synthesis of porous calcium alginate hydrogels, Advanced Materials 18 (2006) 501-504.

[65] C. Palocci, A. Barbetta, A. La Grotta, M. Dentini, Porous biomaterials obtained using supercritical $\mathrm{CO}_{2}$-water emulsions, Langmuir 23 (2007) 8243-8251.

[66] B. Meyssami, M.O. Balaban, A.A. Teixeira, Prediction of $\mathrm{pH}$ in model systems pressurized with carbon dioxide, Biotechnology Progress 8 (1992) 149-154

[67] J.P. Miller, A portion of the system calcium carbonate-carbon dioxide-water with geological implications, American J. Science 250 (1952) 161-203.

[68] J.-Y. Gal, J.-C. Bollinger, H. Tolosa, N. Gache, Calcium carbonate solubility: a reappraisal of scale formation and inhibition, Talanta 43 (1996) 1497-1509.

[69] G.W. Hofland, M. van Es, L.A.M. van der Wielen, G.-J. Witkamp, Isoelectric precipitation of casein using high-pressure $\mathrm{CO}_{2}$, Industrial \& Engineering Chemistry Research 38 (1999) 4919-4927.

[70] K.I. Draget, G. Skjåk Bræk, O. Smidsrød, Alginic acid gels: the effect of alginate chemical composition and molecular weight, Carbohydrate Polymers 25 (1994) 31-38.

[71] L. Pesci, S.M. Glück, P. Gurikov, I. Smirnova, K. Faber, A. Liese, FEBS J. (2015) (submitted for publication).

[72] M. Torre, A.R. Rodriguez, F. Saura-Calixto, Study of the interactions of calcium ions with lignin, cellulose, and pectin, J. Agricultural and Food Chemistry 40 (1992) 1762-1766

[73] C. Tsioptsias, A. Stefopoulos, I. Kokkinomalis, L. Papadopoulou, C. Panayiotou, Development of micro- and nano-porous composite materials by processing cellulose with ionic liquids and supercritical $\mathrm{CO}_{2}$, Green Chemistry 10 (2008) 965.

[74] C. Tsioptsias, C. Panayiotou, Foaming of chitin hydrogels processed by supercritical carbon dioxide, J. Supercritical Fluids 47 (2008) 302-308.

[75] C. Tsioptsias, M.K. Paraskevopoulos, D. Christofilos, P. Andrieux, C. Panayiotou, Polymeric hydrogels and supercritical fluids: the mechanism of hydrogel foaming, Polymer 52 (2011) 2819-2826.

[76] J. Zeltinger, J.K. Sherwood, D.A. Graham, R. Müeller, L.G. Griffith, Effect of pore size and void fraction on cellular adhesion, proliferation, and matrix deposition, Tissue Engineering 7 (2001) 557-572.

[77] M.L. Floren, S. Spilimbergo, A. Motta, C. Migliaresi, Carbon dioxide induced silk protein gelation for biomedical applications, Biomacromolecules 13 (2012) 2060-2072.

[78] N. Annabi, S.M. Mithieux, A.S. Weiss, F. Dehghani, Cross-linked open-pore elastic hydrogels based on tropoelastin, elastin and high pressure $\mathrm{CO}_{2}$, Biomaterials 31 (2010) 1655-1665

[79] N. Annabi, S.M. Mithieux, A.S. Weiss, F. Dehghani, The fabrication of elastinbased hydrogels using high pressure $\mathrm{CO}_{2}$, Biomaterials 30 (2009) 1-7.

[80] T. Østberg, E.M. Lund, C. Graffner, Calcium alginate matrices for oral multiple unit administration: IV. Release characteristics in different media, Internationa J. Pharmaceutics 112 (1994) 241-248.

[81] S.K. Bajpai, S. Sharma, Investigation of swelling/degradation behaviour of alginate beads crosslinked with $\mathrm{Ca}^{2+}$ and $\mathrm{Ba}^{2+}$ ions, Reactive and Functional Polymers 59 (2004) 129-140.

[82] M. Martins, A. Barros, S. Quraishi, S.P. Raman, P. Gurikov, I. Smirnova, A.R.C Duarte, R.L. Reis, submitted for publication.

[83] Y.S. Choi, S.R. Hong, Y.M. Lee, K.W. Song, M.H. Park, Y.S. Nam, Study on gelatin-containing artificial skin: I. Preparation and characteristics of nove gelatin-alginate sponge, Biomaterials 20 (1999) 409-417.

[84] A.R. Kulkarni, K.S. Soppimath, T.M. Aminabhavi, A.M. Dave, M.H. Mehta, Glutaraldehyde crosslinked sodium alginate beads containing liquid pesticide for soil application, J. Controlled Release 63 (2000) 97-105.

[85] S.K. Bajpai, R. Tankhiwale, Investigation of water uptake behavior and stability of calcium alginate/chitosan bi-polymeric beads: Part-1, Reactive and Functional Polymers 66 (2006) 645-658.

[86] H. Isaksson, C.C. van Donkelaar, K. Ito, Sensitivity of tissue differentiation and bone healing predictions to tissue properties, J. Biomechanics 42 (2009) 555-564.

[87] R.P. Viggiano, D.A. Schiraldi, Fabrication and mechanical characterization of lignin-based aerogels, Green Materials 2 (2014) 153-158.

\section{6}

717

718

719

721

72

\section{725}

\section{2}

$$
\begin{aligned}
& 727 \\
& 728 \\
& 729
\end{aligned}
$$

$$
\begin{aligned}
& 729 \\
& 730
\end{aligned}
$$

$$
\begin{aligned}
& 730 \\
& 731 \\
& 732
\end{aligned}
$$

\section{${ }_{733}^{732}$}

$$
\begin{aligned}
& 735 \\
& 736
\end{aligned}
$$

$$
\begin{array}{r}
736 \\
737 \\
738
\end{array}
$$$$
\begin{aligned}
& 738 \\
& 739
\end{aligned}
$$

739
740
741

$$
\begin{aligned}
& 742 \\
& 743 \\
& 744
\end{aligned}
$$

$$
\begin{aligned}
& 744 \\
& 745 \\
& 746
\end{aligned}
$$

\section{747
748}

748

$$
\begin{aligned}
& 749 \\
& 750 \\
& 751 \\
& 752 \\
& 753
\end{aligned}
$$

\section{759
760}

$$
\begin{aligned}
& 759 \\
& 760 \\
& 761
\end{aligned}
$$

$$
\begin{aligned}
& 761 \\
& 762 \\
& 763 \\
& 764
\end{aligned}
$$$$
\begin{aligned}
& 762 \\
& 763 \\
& 764
\end{aligned}
$$

$$
\begin{aligned}
& 765 \\
& 766 \\
& 767
\end{aligned}
$$

$$
\begin{aligned}
& 766 \\
& 767 \\
& 768 \\
& 769
\end{aligned}
$$$$
\begin{aligned}
& 768 \\
& 769 \\
& 770
\end{aligned}
$$

$$
\begin{aligned}
& 770 \\
& 771 \\
& 772 \\
& 773
\end{aligned}
$$$$
\begin{aligned}
& 772 \\
& 773 \\
& 774
\end{aligned}
$$

775
774
775
77

$$
\begin{aligned}
& 775 \\
& 776 \\
& 777 \\
& 778
\end{aligned}
$$$$
778
$$

$$
\begin{aligned}
& 779 \\
& 780 \\
& 781 \\
& 782 \\
& 783
\end{aligned}
$$

7

$$
\begin{aligned}
& 784 \\
& 785 \\
& 786 \\
& 787
\end{aligned}
$$

$$
\begin{aligned}
& 786 \\
& 787 \\
& 788
\end{aligned}
$$

$$
\begin{aligned}
& 788 \\
& 789 \\
& 790
\end{aligned}
$$

$$
\begin{aligned}
& 789 \\
& 790 \\
& 791 \\
& 792
\end{aligned}
$$$$
\begin{aligned}
& 791 \\
& 792 \\
& 793
\end{aligned}
$$

$$
\begin{aligned}
& 793 \\
& 794 \\
& 795 \\
& 796 \\
& 797
\end{aligned}
$$

$$
\begin{aligned}
& 796 \\
& 797 \\
& 798 \\
& 799 \\
& 800 \\
& 801
\end{aligned}
$$

